\title{
A Steady-State Contingency Analysis of the SADC Regional Grid Using the N-1 Criterion
}

\author{
Stacey Juliana Tombozi Mwale and Innocent Ewean Davidson \\ Eskom Centre of Excellence in HVDC Engineering, School of Engineering, University of KwaZulu-Natal, Durban 4001, South Africa
}

Received: November 14, 2014 / Accepted: December 08, 2014 / Published: May 31, 2015.

\begin{abstract}
Southern Africa has experienced electric power deficits over the last decade. This has been due in part to the member countries' inadequate electrical power supply system, as well as load growth in areas which were not adequately planned for. This has induced the formation of organizations such as SADC (Southern African Development Community) and SAPP (Southern African Power Pool) that have the common goal of achieving development and economic growth in the region which comprises of 15 member countries. This paper presents results from a security analysis of the region's electric power supply system using a baseline level of performance. This was carried out by performing a steady-state contingency analysis on a SADC power network model subject to the $\mathrm{N}-1$ criteria which expresses the ability of the power network to experience a contingency without causing an overload or failure in any other part of the network. Simulations were carried out using DigSilent.
\end{abstract}

Key words: N-1 criteria, power deficits, security analysis, contingency analysis.

\section{Introduction}

The SADC (Southern African Development Community), formally known as the SADCC (Southern African Development Coordination Conference), is an organization that was created in Lusaka, Zambia on April 1st 1980 with the main aim of coordinating development projects in order to minimize economic dependence on the apartheid South Africa [1]. Its members consist of the 15 countries namely: Angola, Botswana, Swaziland, Tanzania, Zambia, The Democratic Republic of Congo, Lesotho, Madagascar, Malawi, South Africa, Zimbabwe, Mauritius, Namibia, Mozambique and Seychelles (Fig. 1). The region has been experiencing major power shortages since 2006 due to a combination of factors which have contributed to diminishing generation reserve capacity against an increasing growth in demand [2]. This is undesirable and has a negative impact on industries, social services, trade and

Corresponding author: Innocent Ewean Davidson, director, research fields: modern electric power systems, smart grids and clean energy technologies. E-mail: Davidson@ukzn.ac.za. economic development of the region. Power outages and poor quality of supply are often the result of insufficient generation capacity or poor operation of the power system.

Security refers to the degree of risk in a power system's ability to withstand imminent disturbances or contingencies without interruption to customer service [3]. It relates to robustness of the system to imminent disturbances and depends on the system operating condition as well as the contingent probability of disturbances [4]. Security assessment can be carried out statistically or dynamically. Power system steady state security is an instantaneous condition as it is a function of time and of the robustness of the system with respect to the imminent disturbances. For economic development of any given society or community, it is imperative that, there is a reliable electric power supply. Some of the factors that threaten the reliability of the network include aging infrastructure of both the transmission and distribution networks [5]. A method of ensuring a reliable power network is by careful monitoring, automation and 


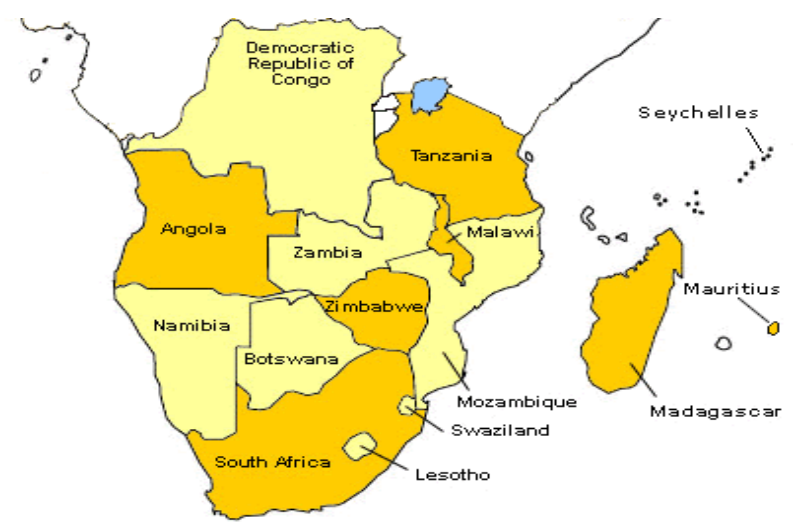

Fig. 1 Member countries of SADC.

information management. One such tool that can be used in that regard is contingency analysis.

This is the study of the outage of elements such as transmission lines, transformers and generators, and investigation of the resulting effects on line power flows in the remaining parts of the system network.

\section{SADC'S Average Power Per Capita}

This is the average energy consumption of electric power generated per person in a particular region or country, calculated using the formula [6]:

$$
P_{A V}=P_{G} / P_{T}
$$

where, $P_{A V}=$ average power per capita $(\mathrm{W}) ; P_{G}=$ electric power consumption $(\mathrm{kWh}) ; P_{T}=$ total population.

Table 1 shows the average power per capita consumption for SADC countries in 2011.

\section{Techno-economic Review of SADC}

\subsection{SADC Interconnections}

The 12 member countries of SAPP (Southern African Power Pool) are interconnected. Fig. 2 shows the transmission grid interconnections between each country that allows for the import/export of electrical power between them. These electric power bilateral contracts are agreements made between parties in the act of power exchange or purchase. African countries began trading electric power in the 1950's with the line connecting DRC (Democratic Republic of Congo) and Zambia. Interconnections between Zambia and Zimbabwe were established following the construction of the Kariba Dam in the 1960 's. In 1975, South Africa was connected via a $533 \mathrm{kV}$ HVDC (high voltage direct current) line to Mozambique [7].

Table 1 SADC average power per capita (2011).

\begin{tabular}{llllll}
\hline Country/utility & $\begin{array}{l}\text { 2011 Population } \\
\text { (million) }\end{array}$ & $\begin{array}{l}\text { Total genera-ting } \\
\text { capacity (MW) }\end{array}$ & Peak demand (MW) $\begin{array}{l}\text { Electric energy } \\
\text { consumption (billion -2011 }\end{array}$ & $\begin{array}{l}\text { Average power per } \\
\text { capita } \\
\text { (MW) }\end{array}$ \\
\hline Angola & 19.62 & $1,217.4$ & 688 & 3.17 & 18.44 \\
Botswana & 2.03 & 132 & 580 & 2.65 & 149.02 \\
DRC & 67.67 & $1,846.8$ & 1,028 & 6 & 10.12 \\
Lesotho & 2.19 & 72 & 120 & 0.52 & 27.11 \\
Madagascar & 23.32 & 234.67 & - & 0.97 & 4.75 \\
Malawi & 15.38 & 350.8 & 344 & 1.57 & 11.65 \\
Mauritius & 1.28 & 382.84 & 484 & 2.16 & 192.64 \\
Mozambique & 23.9 & 2,182 & 530 & 10.16 & 48.53 \\
Namibia & 2.32 & 493 & 530 & 2.85 & 140.23 \\
Seychelles & 0.9 & 95 & 69 & 0.23 & 29.17 \\
Swaziland & 1.07 & 60.4 & 200 & 1.27 & 135.49 \\
South Africa & 50.59 & $43,934.16$ & 33,088 & 215.1 & 485.37 \\
Tanzania & 46.22 & 460 & 828.58 & 3.18 & 7.85 \\
Zambia & 13.47 & 1,575 & 1,800 & 8.84 & 74.92 \\
Zimbabwe & 12.75 & 2,045 & 2,200 & 10.89 & 97.50 \\
\hline Total & 282.7 & $55,081.07$ & $42,489.58$ & 269.56 & $1,432.80$ \\
Average & 18.85 & $3,672.07$ & $2,832.64$ & 17.97 & 95.52 \\
\hline
\end{tabular}




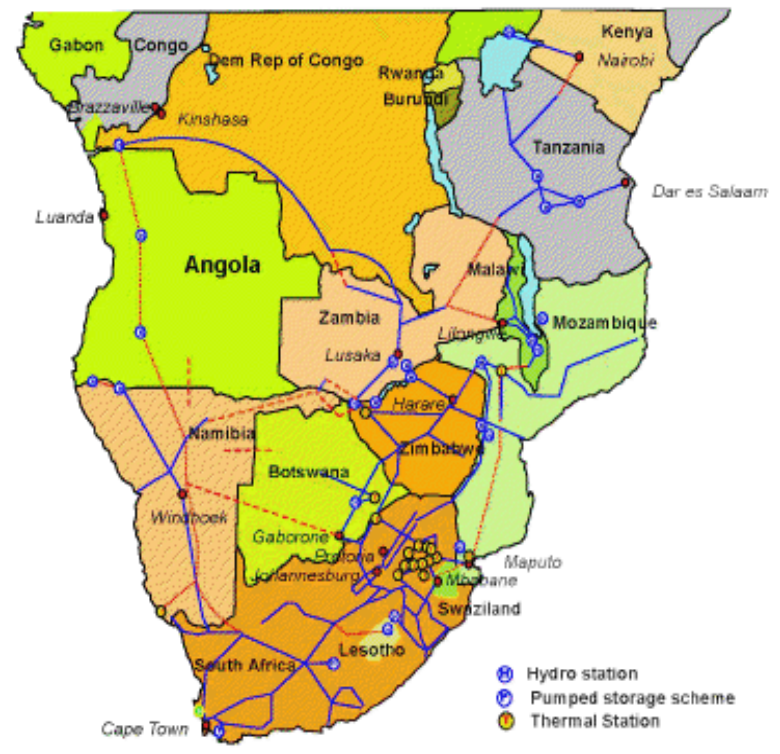

Fig. 2 Electrical interconnection in SADC.

\subsection{Access to Electricity}

Demand for electricity in Southern Africa is increasing at a growth rate of $3 \%$ per annum due to increased economic activities resulting in diminishing surplus capacity [8]. This indicates a lack of adequate access to electricity for some of the population in the region. Access to electricity implies [9]:

- having access to a distribution (grid) supply;

- having an affordable price of electricity;

- having a provision of quality energy service.

Over the years, the SADC region has experienced very low access to electricity in spite of its abundant resources which include hydro, solar, coal and biomass [10]. While, there has been an improvement in the regions' accessibility to electricity (from $28.5 \%$ in 2005 to $38.24 \%$ in 2009), there remains a huge deficit which may be reduced if the region's resources were fully harnessed and optimally utilized to generate more electricity.

\subsection{Inflation in $S A D C$}

Inflation is the rapid increase in the prices of goods and services in an economy over a period of time. When the general price level increases means that fewer goods can be bought in each unit of currency [11]. This also applies to the cost of purchasing electricity. If a country is prone to higher levels of inflation then the price of electricity is also going to be slightly higher [12].

The world experienced a global financial meltdown from 2008-2012. This resulted in widespread unemployment, high federal debts, declined in property prices, increased in the prices of oil, food and electricity. The SADC region was impaired with an electrical supply deficit of $969 \mathrm{MW}$ in 2009 and has since increased to $6,000 \mathrm{MW}$ [13].

It can be inferred that, the increase in electrical supply deficit in the SADC region occurred not due to increased inflation but due to increased electricity demand in the member countries as they experienced high population growth rates during that period. Over the last year (2012), the region has had a growth rate of $5 \%$ only resulting in a general increase of demand for electricity in each country. Table 2 provides an overview of the socio-economic status of SADC member countries.

\subsection{GDP (Gross Domestic Product)}

GDP also known as GDI (gross domestic income) is the measure of the nation's income and output for a given period of time, usually annually.

It includes all private/public consumption, government expenses, investments and exports (less imports) that occur within a defined territory. GDP can be calculated using Eq. (2) [14]:

$$
\mathrm{GDP}=C+G+I+N X
$$

where, $C$ is private consumption in a nation's economy; $G$ is the sum of government spending; $I$ is the sum of all the country's businesses spending on capital; $N X$ is the nation's total net exports.

GDP is one of the primary indicators used to determine the economic health of a country. A decline in GDP in a country indicates that the economy is experiencing a low level of services which includes the energy sector. 
Table 2 SADC socio-economic review (2011).

\begin{tabular}{llllll}
\hline Country & $\begin{array}{l}2011 \text { population } \\
\text { (million) }\end{array}$ & Inflation rates (\%) & $\begin{array}{l}\text { GDP } \\
\text { (billion US\$) }\end{array}$ & $\begin{array}{l}\text { Per capita income } \\
\text { (US\$/person) }\end{array}$ & Income level \\
\hline Angola & 19.62 & 9.02 & 101 & $5,147.81$ & Upper middle \\
Botswana & 2.03 & 7.4 & 17.63 & $8,684.73$ & Upper middle \\
DRC & 67.67 & 6.9 & 15.64 & 231.12 & Low \\
Lesotho & 2.19 & 8.73 & 2.43 & $1,109.59$ & Lower middle \\
Madagascar & 23.32 & 5.9 & 9.95 & 426.67 & Low \\
Malawi & 15.38 & 28.3 & 5.7 & 370.61 & Low \\
Mauritius & 1.28 & 3.1 & 11.31 & $8,835.94$ & Upper middle \\
Mozambique & 23.9 & 2.02 & 12.8 & 535.56 & Low \\
Namibia & 2.32 & 6.3 & 12.3 & $5,301.72$ & Upper Middle \\
Seychelles & 0.9 & 5.8 & 1 & 1111.11 & Lower middle \\
Swaziland & 1.07 & 9 & 3.98 & $3,719.63$ & Lower middle \\
South Africa & 50.59 & 5.6 & 408.2 & $8,068.79$ & Upper middle \\
Tanzania & 46.22 & 12.1 & 23.71 & 512.98 & Low \\
Zambia & 13.47 & 6.9 & 19.21 & $1,426.13$ & Lower middle \\
Zimbabwe & 12.75 & 2.91 & 9.91 & 777.25 & Low \\
\hline Total & 282.7 & & 654.77 & $46,259.65$ & $3,083.97$ \\
Average & 18.85 & & 43.05 & & \\
\hline
\end{tabular}

\subsection{Income Level}

The income level of a country refers to budget constraints based on the median household income which the government agency uses to provide limits to tax credits and affordable housing. Income levels can be classified as low income, lower middle income, upper middle income and high income. Low and middle income nations are often referred to as developing countries.

According to the World Bank Atlas method, the separate levels defined as [15]:

$e_{t}^{*}=\frac{1}{3}\left[e_{t-2}\left(\frac{P_{t}}{P_{t-2}} / \frac{P_{t}^{S \$}}{P_{t-2}}\right)+e_{t-1}\left(\frac{P_{t}}{P_{t-1}} / \frac{P_{t}^{S \$}}{P_{t-1}^{S \$}}\right)+e_{t}\right]$

The calculation of GNI (gross national income) per capita in U.S. dollars for year $t$ [15]:

$$
Y_{t}^{\$}=\left(Y_{t} / N_{t}\right) / e_{t}^{*}
$$

where, $e t^{*}$ is the Atlas conversion factor (national currency to the US\$) for year $t ; e_{t}$ is the average annual exchange rate (national currency to the US\$) for year $t$; $p^{t}$ is the GDP deflator for year $t ; p_{t}^{S S}$ is the SDR (special drawing rights) deflator in U.S. dollar terms for year $t$;
$Y_{t}^{\$}$ is the Atlas GNI per capita in U.S. dollars in year $t$; $Y_{t}$ is current GNI (local currency) for year $t$; and $N_{t}$ is the midyear population for year $t$.

\section{Security Analysis of SADC Region}

Contingency analysis is the evaluation of the violations in operating systems (if any) that certain contingencies can pose to the electrical power system [16]. There are many methods that are used in order to analyse the contingency of any power network system [17] Contingency analysis is a computer application that uses a simulated model of the power system to evaluate the effects, calculate any overloads and assess the ability of the grid to withstand cascading component failures/contingencies [18]. In carrying out the assessment of SADC power network security status, a contingency analysis was performed on the design model based on some assumptions. First, this is a steady-state simplified analysis. Second, the analysis did not take into consideration, the various grid codes in all the countries. For example, in the South African grid code, the Koeberg nuclear power station is required to always have $\mathrm{N}-2$. Furthermore, for a loss of 
1,000 MW, there will be under frequency problem. These are major criteria in network design. Third, the impact of reactive compensation was not considered in this analysis. The results of contingency analysis provide the basis for preventive and corrective operation actions against blackouts [19]. It can be referred to as the "what if" scenario. Using the power factory contingency analysis tool, the performance of the SADC power system was assessed, after a major failure of the generators in selected SADC countries experienced a failure.

\section{Design Model and Methodology}

DigSilent power factory software was used in the design and simulation of the SADC power network model. The model was built using data for generating plants and delivery network data obtained for each country. Madagascar, Seychelles and Mauritius were not modelled as they are not directly interconnected to other countries of the SADC region.

Each country was represented as a mega-substation in the design model with all the generating units in each country connected to one busbar (representing the country's grid). In this model, the peak demand for each country was taken to be the country's total load and simulated. The SADC region is represented in the complete model in Fig. 3. Fig. 4 shows an example (Mozambique) as a sub-model for analysis.

\section{Simulation Results}

Contingency analysis was performed on the SADC power system design model, taking into consideration the N-1 criterion. Results obtained are analysed and discussed. Fig. 5 shows the behaviour of the SADC power network during a major contingency (loss of entire generation) in Zambia. This was randomly chosen as one of the case-study examples to illustrate the behaviour of the regional network, and line flows to verify the security of the SADC power system. The model was simulated with all Zambia's generators assumed to be faulty and hence disconnected. This was

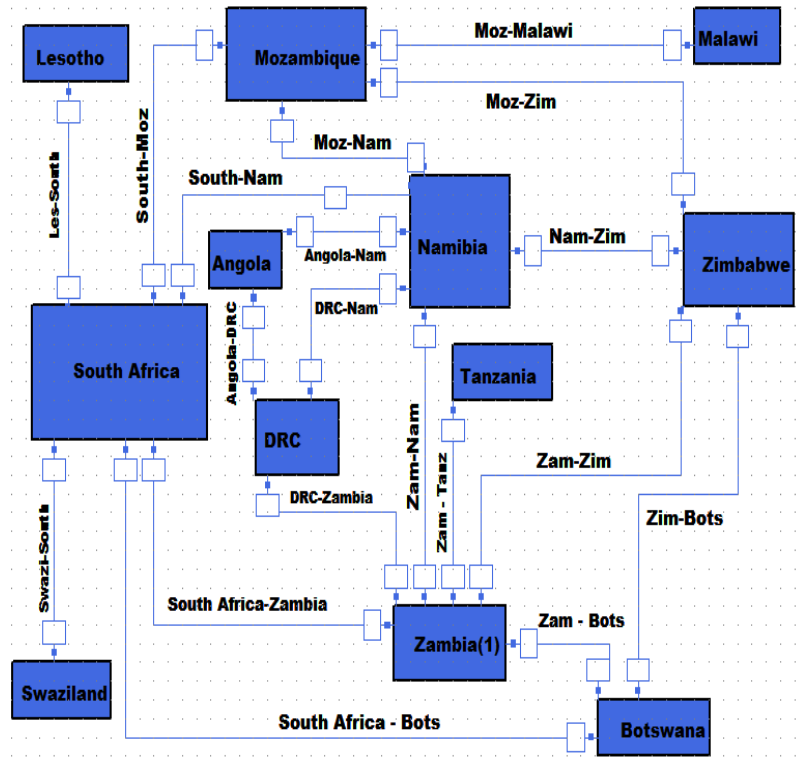

Fig. 3 SADC power system network model.

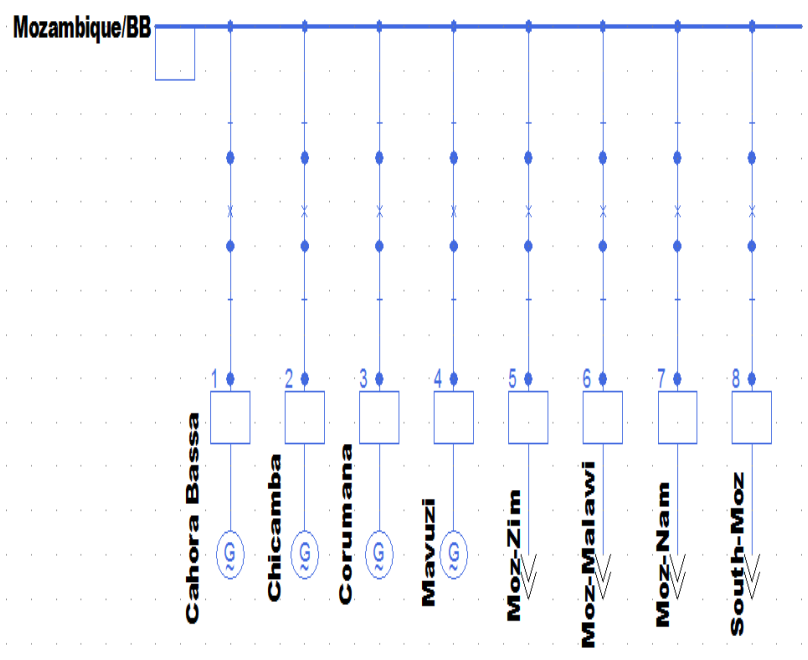

Fig. 4 Mozambique power system network model.

done to satisfy the $\mathrm{N}-1$ criterion which requires an outage in one of the major linkages to verify whether or not the delivery system will experience an overload or failure in any other part of the network. Should this occur, the network is said to be unsecure.

Fig. 5 shows the power flows for each transmission line or grid interconnecting the 12 countries.

The interconnection lines indicate the line has a loading range of over $100 \%$ and hence is overloaded. Orange indicates a load range of over $80 \%$ and black, less than $80 \%$. Fig. 5 indicates that, the transmission lines were overloaded with the exception 


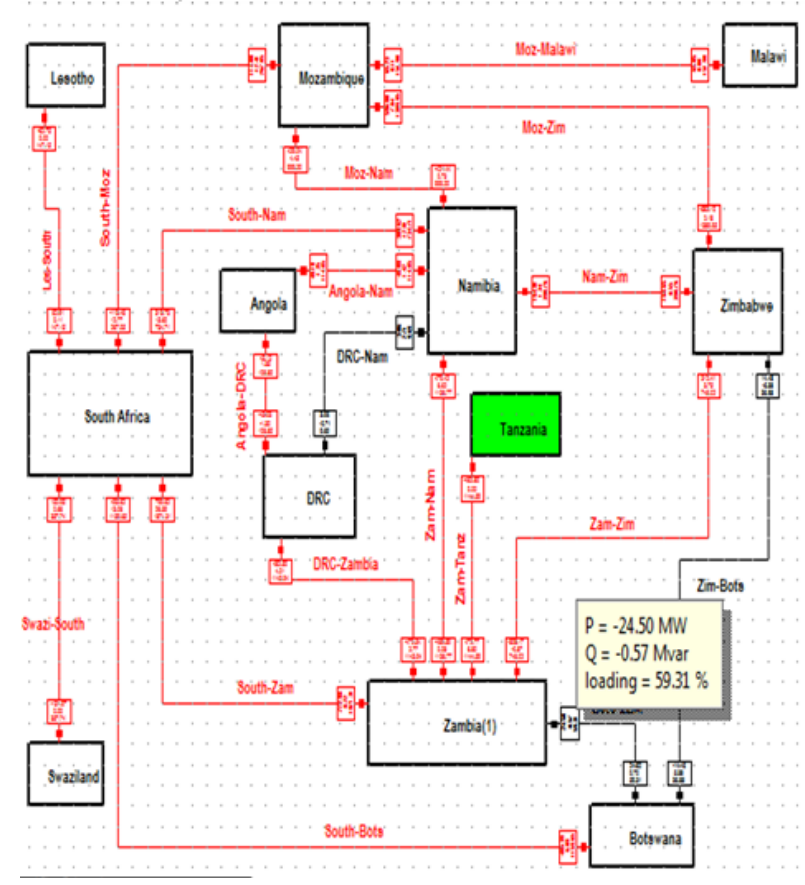

Fig. 5 Loss of entire elecricity generation in Zambia.

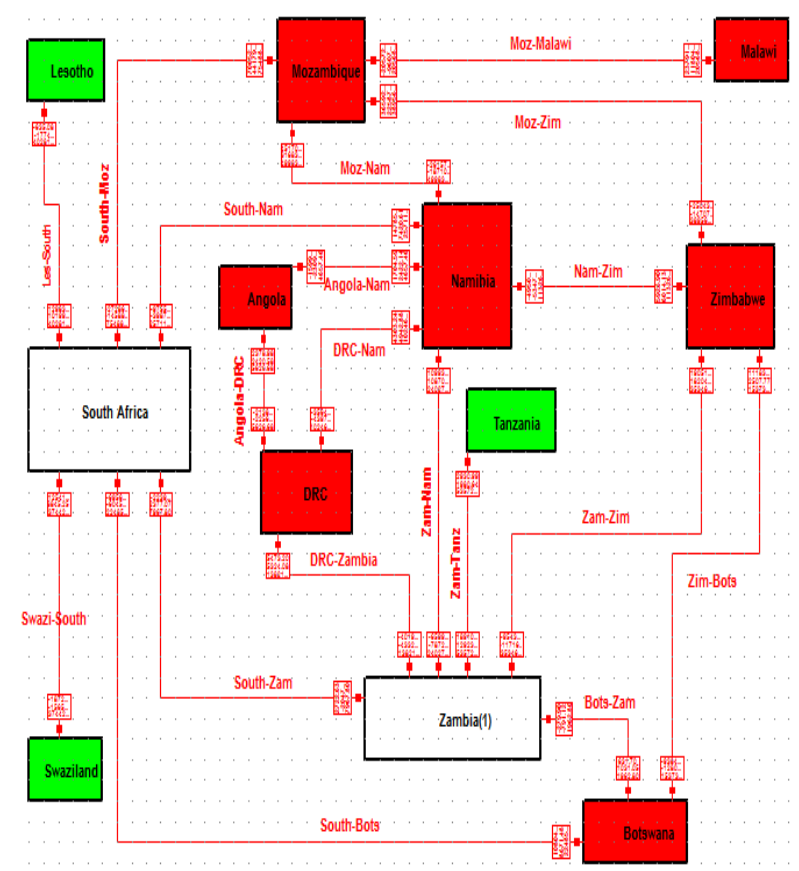

Fig. 6 Loss of entire electricity generation in South Africa.

of Zimbabwe-Botswana, DRC-Namibia, Botswana-Zimbabwe transmission lines, which are under-loaded. The inset box (Fig. 5) shows the realand reactive power and the loading range in percentage for the Botswana-Zambia transmission line at the Zambian termination. It indicates a negative real power flow of $24.50 \mathrm{MW}$. The negative sign indicating insufficient generation of electrical power from Zambia hence the country is importing 24.50 MW from Botswana. The insert also shows a reactive power of -0.57 MVAR (mega volt ampere reactive) flowing in the opposite direction and a loading percentage of $59.31 \%$.

Fig. 5 shows the line flows after a contingency occurs with the loss of South Africa's generators, which accounts for over 75\% of SADC's power generation. A loss of South Africa's generation resulted in the overloading of all interconnections in the region. IEEE (Institute of Electrical and Electronic Engineers) 1453-2004 standard specifies that the voltage at each bus bar between the nations should be kept within 95\% and 105\% (0.95 p.u. (per unit) and 1.05 p.u.) of its nominal voltage value.

During an emergency (outage of generators) as simulated in our model, the thermal rating of equipment should not be exceeded; and the voltage kept within statutory limits. Fig. 6 shows that, Swaziland, Lesotho and Tanzania had voltage levels dropping below the standard (highlighted in green). Countries with red highlights (Angola, Botswana and Malawi) had voltages exceeding the upper limit of the standard after the contingency occurred.

\section{Conclusions}

The contingency analysis carried out shows that, in the event of a major disturbance (or fault) in any one component of the network will result in overloading several interconnections making the network not secure. In extreme contingencies, this will lead to violations of statutory voltage and thermal limits. This contingency study simulates steady state network conditions. A dynamic analysis will be catered for in future work.

Electricity demand in the SADC region continues to grow each year partly due to population growth. This remains a major challenge to the power network operators in the region. However, initiatives taken by 
governments in the region to aggressively invest in new power generation infrastructure will assist in alleviating the problem of electricity shortages, while, increasing power accessibility, which is one of SAPP's main strategic objectives. These initiatives will enhance the security of the SADC power network and reduce the power deficit in the region. Proposed solutions include increasing generation capacity of member countries, strengthening existing delivery systems, and providing more strategic interconnections to facilitate power exchange between the member states.

\section{References}

[1] Cawthra, G. 2010. The Role of SADC in Managing Political Crisis and Conflicts: The Case of Madagascar and Zimbabwe. Maputo: Friedrich Ebert Publishers.

[2] Sikuka, K. 2010. "Nam Energy Projects Showcased at German Investment Conference." The Namibian Newspaper, March 8.

[3] Bose, A., and Tomsovic, K. 1999. Power System Security. Washington DC: Washington State University.

[4] Kundur, P. 2004. "Definitions and Classifications of Power System Stability, IEEE/CIGRE Joint Task Force on Stability and Definitions." IEEE Transactions on Power Systems 19 (2): 1387-401.

[5] Ipakchi, A. 2007. Implementing the Smart Grid: Enterprise Information Integration. New Mexico: Grid-Interop Forum.

[6] Denholm, P., and Margolis, R. 2007. The Regional Per Capita Solar Electric Footprint for the United States. Colorado: National Renewable Energy Laboratory.

[7] Musaba, L. 2005. "The Development of the SAPP Competitive Electricity Market." In Proceedings of the Inaugural IEEE PES 2005 Conference and Exposition in Africa, 188-94.

[8] Musaba, L. 2008. "Challenge of Capacity Growth in the
Southern African Power Pool." Presented at the RERA (Regional Electricity Regulators Association) Commissioner Training, Lusaka, Zambia.

[9] Pachauri, S., and Spreng, D. 2004. "Energy Use and Energy Access in Relation to Poverty." Economic and Political Weekly 39 (3): 271-8.

[10] Davidson, O., and Mwakasonda, S. A. 2004. "Electricity Access for the Poor: A Study of South Africa and Zimbabwe." Energy for Sustainable Development 8 (4): 26-40.

[11] Heberter, G. 1960. Inflation: Its Causes and Cures. Washington DC: American Enterprise Association.

[12] Levell, P., and Oldfield, Z. 2011. The Spending Patterns and Inflation Experience with Low Income Households over the Past Year. London: The Institute for Fiscal Studies.

[13] Esterhuizen, I. 2012. "Public, Private Investment Needed to Tackle SADC Power Deficit." Engineering News, September 11. Accessed August 14, 2013. http://www.engineeringnews.co.za.

[14] Andolfatto, D. 2005. Macroeconomic Theory and Policy. Surrey: Simon Fraser University.

[15] The World Bank. 2013. Atlas Conversion Factor. The World Bank. Accessed September 20, 2013. http://data.worldbank.org/about/country-classifications/w orld-bank-atlas-method.

[16] Ahmad, S., Zakaria, N. M., Ashik, E., and Biswas, G. A. K. 2011. Contingency Analyse and Reliability Evaluation of Bangladesh Power System. Dhaka: BRAC University.

[17] Khardenvis, M. D., Pande, V. N., and Jape, V. M. 2011. "Transmission Network Expansion Planning Using Contingency Analysis." In Proceedings of the ICEEA (International Conference on Environmental Engineering and Applications), 270-4.

[18] Chen, Y. 2011. "Graphical Contingency Analysis Tool." Presented at the EMS (European Meeting of Statisticians) Conference Meeting, Pennsylvania, USA.

[19] Knight, U. G. 2000. Power Systems in Emergencies from Contingency Planning to Crisis Management. New York: John Wiley. 